\title{
Myotonic Dystrophy Type 1 Complicated With Peripheral Arterial Occlusive Disease: A Case Report
}

\author{
Dong Hun Lee, MD, Dong Sik Park, MD, Dong Hyun Kim, MD, Sang Hun Lee, MD, Hee Mun Cho, MD
}

Department of Rehabilitation Medicine, Kangdong Sacred Heart Hospital, Hallym University College of Medicine, Seoul, Korea

Myotonic dystrophy (MD) is the most common adult muscular dystrophy characterized by multi-systemic clinical manifestations involving the brain, smooth muscle, cardiovascular and endocrine systems. However, peripheral arterial occlusive disease (PAOD) is an uncommon presentation of MD type 1 (DM1), which has not been reported in recent literature. A 53-year-old female, previously confirmed as DM1, presented with vague claudication of both lower limbs. The diagnosis of PAOD based on results of ankle-brachial index, ultrasonography, and abdominal computed tomography angiography studies was followed by aortobifemoral artery bypass surgery. Although the arterial patency was restored after the operation, she did not recover from post-operative respiratory complications. Screening of PAOD is necessary for DM1 with general risk factors of occlusive arteriopathy. However, surgery should be reserved for the most severe cases.

Keywords Myotonic dystrophy, Peripheral arterial occlusive disease

\section{INTRODUCTION}

Myotonic dystrophy type 1 (DM1) presents multi-systemic clinical manifestations such as cataracts, heart conduction defects, hypogonadism, mental retardation, endocrinonogical disorders, and insulin resistance [1]. Insulin resistance in DM1 has been associated with aberrant splicing of the mutated dystrophia myotonica

Received April 3, 2014; Accepted September 17, 2014

Corresponding author: Dong Hyun Kim

Department of Rehabilitation Medicine, Kangdong Sacred Heart Hospital, Hallym University College of Medicine, 445 Gil-dong, Gangdonggu, Seoul 134-701, Korea

Tel: +82-2-2224-2210, Fax: +82-2-473-8101, E-ail: skyler02@hallym.or.kr

(c) This is an open-access article distributed under the terms of the Creative Commons Attribution Non-Commercial License (http://creativecommons. org/licenses/by-nc/4.0) which permits unrestricted noncommercial use, distribution, and reproduction in any medium, provided the original work is properly cited.

Copyright (C) 2015 by Korean Academy of Rehabilitation Medicine protein kinase (DMPK) gene [2], whereas features of metabolic syndrome are less likely to occur in DM1. Atherosclerosis is also an unusual clinical presentation in DM1 patients [1].

Any association between myotonic dystrophies and occlusive arteriopathy has not been previously reported. Nonetheless, the likelihood of peripheral arterial occlusive disease (PAOD) is presumed to be lower in DM1, as compared to myotonic dystrophy type 2 (DM2) due to the known smaller incidence of dyslipidemia and atherosclerosis $[1,3]$.

We herein report a case of DM1 with PAOD that appears to be associated with long standing dyslipidemia, cigarette smoking, and physical inactivity. 


\section{CASE REPORT}

A 53-year-old female patient diagnosed with DM1 was transferred to the rehabilitation medicine department due to gait disturbance. She presented with myotonia, disabling distal weakness, dysarthria, dysphagia, dementia, and cataract. Dominant limb weakness started about a year prior. Since then she was housebound, and experienced difficulty in sit to stand with visible gait deviation which developed for the past 6 months. Anthropometric data at initial admission revealed a height of $160 \mathrm{~cm}$, and weight of $46 \mathrm{~kg}$ with equivalent body mass index $18 \mathrm{~kg} /$

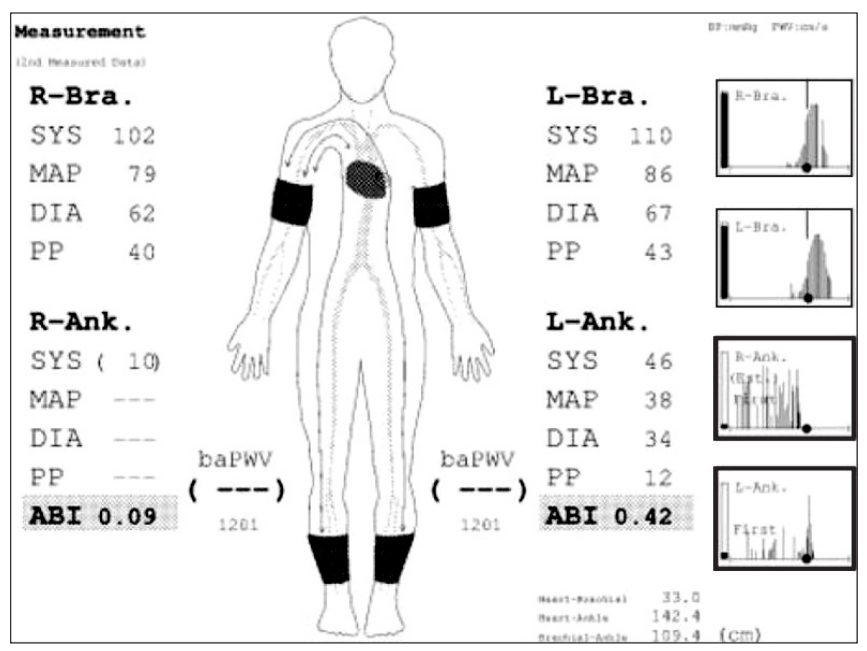

Fig. 1. Ankle-brachial index (ABI) values were 0.09 on right side and 0.42 on left side. $\mathrm{m}^{2}$. Initial blood test showed total cholesterol $353 \mathrm{mg} /$ $\mathrm{dL}$, triglyceride $418 \mathrm{mg} / \mathrm{dL}$, LDL cholesterol $147 \mathrm{mg} / \mathrm{dL}$, HDL cholesterol $39 \mathrm{mg} / \mathrm{dL}$, blood glucose $105 \mathrm{mg} / \mathrm{dL}$, but parameters reflecting liver and thyroid function were within normal range. Clinical signs concerned with diabetes were not detected. She had been taking oral statin for 2 years before the admission. On electromyography, denervation potentials and myotonic discharges were evident in all tested muscles. Southern blot analysis revealed about 650 trinucleotide (CTG) repeats expansion in the DMPK gene. She was diagnosed as DM1. She had a smoking history of 7 pack/year and alcohol abuse for the past 10 years.

In the course of rehabilitation, she intermittently complained of vague claudication of both lower limbs. Physical exam revealed weak pulsation of dorsalis pedis arteries with pale coloration of both ankles. Under the impression of deep vein thrombosis or PAOD, the following studies were performed. Ankle-brachial index (ABI) values were 0.09 on right side and 0.42 on left side (Fig. 1). Duplex ultrasonography study of lower extremity revealed a pulsus tardus parvus on femoral, popliteal, tibial and dorsalis pedis arteries (Fig. 2). Three-dimensional reconstructed abdomen computed tomography (CT) angiography showed concentric wall thickening and tapering occlusion in the distal abdominal aorta at $3.5 \mathrm{~cm}$ below the renal artery (Fig. 3A). Under the impression of PAOD, she was advised to undergo bypass surgery from a thoracic surgery specialist. Preoperative pulmonary func-
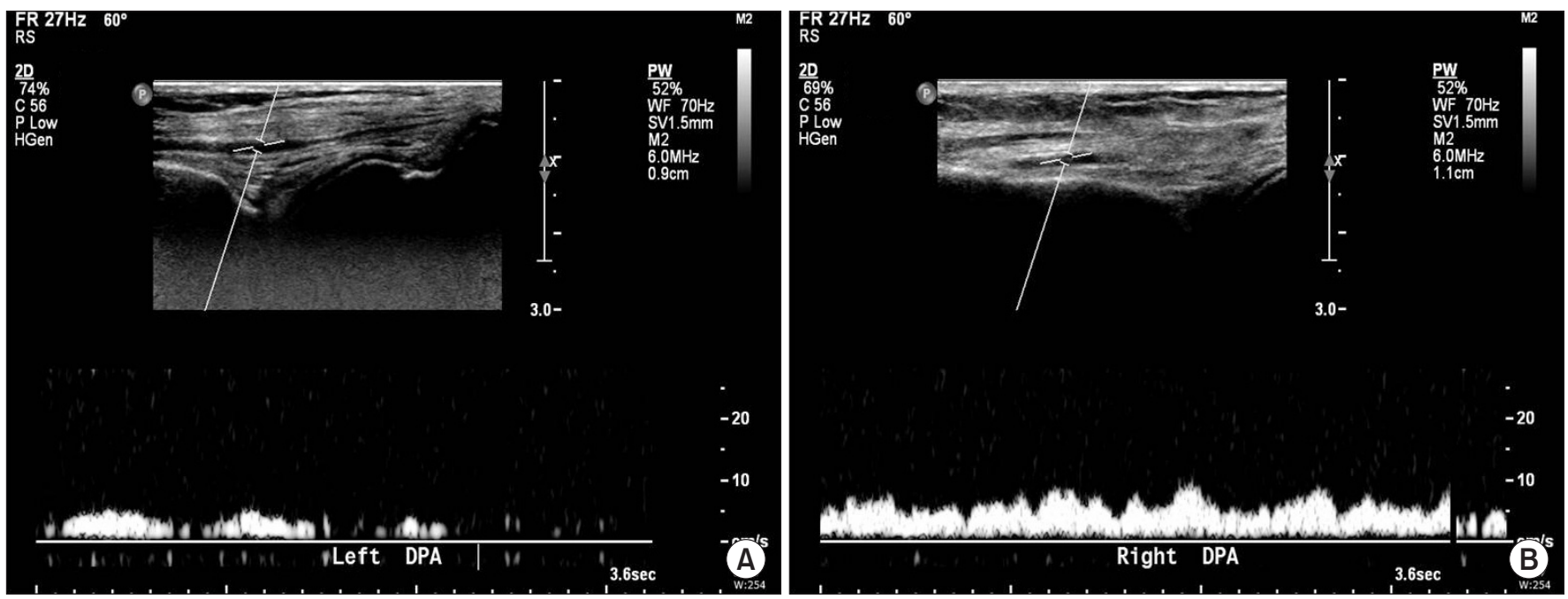

Fig. 2. Ultrasonography on lower extremity showed decreased blood flow at left dorsalis pedis artery (A) and right dorsalis pedis artery $(\mathrm{B})$. 

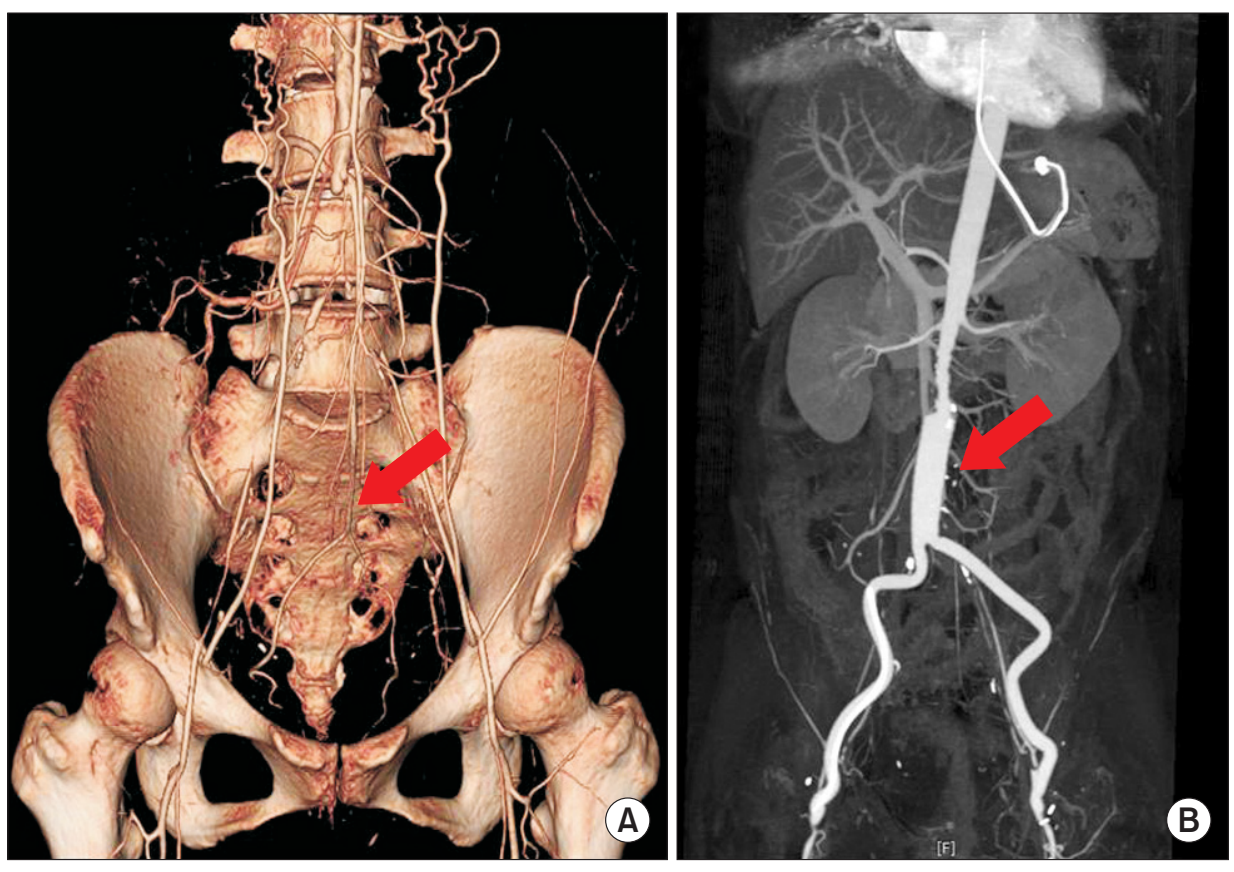

Fig. 3. Three-dimensional reconstructed abdomen computed tomography angiography showed tapering occlusion in the distal abdominal aorta at $3.5 \mathrm{~cm}$ below the renal artery (A). Postoperative finding shows patent lumen at operation site of bypass arterial graft (B).

tion test showed severe restrictive pattern (FVC, 42\%; $\mathrm{FEV}_{1}, 47 \%$ ). The expected high cardiopulmonary risks of general anesthesia and surgery made us reluctant to conduct bypass surgery. However, due to diffuse extensive occlusive lesions and the patient's strong desire for the surgery, aortobifemoral artery bypass was performed. Biopsy showed fibrous wall thickening with intimal yellow patch lesion, confirmative of PAOD. Postoperative CT angiography showed patent lumen of the bypassed artery (Fig. 3B). However, she did not recover from the post-operative respiratory complications, and died of respiratory failure 54 days after the operation.

\section{DISCUSSION}

DM1 results from an unstable repetition expansion of CTG in the DMPK gene located at chromosome 19q13.3, whereas DM2 is due to an unstable 4 nucleotide repeat expansion (CCTG)n in intron 1 of CNBP/ZNF9 on chromosome 3q21.3. [2-4].

Although manifestations of DM1 and DM2 share a spectrum of similar presenting symptoms, clinical course of DM2 is considered to be more favorable except for certain distinguishing features, such as abnormal lipid profile [2]. Atherosclerosis and related hyperlipidemia that is closely related to insulin resistance is frequently seen in DM2 $[2,4]$, whereas there is no obvious increase in DM1 patients [1]. The reasons for the lower incidence are unclear.

Adiponectin, a metabolic regulator protein, tends to be decreased in DM1 due to mutant transcription and may subsequently lead to increased insulin resistance $[5,6]$. Nevertheless, the reasons for the low incidence of cardiovascular disease and atherosclerosis in DM1 are unknown [1]. Findings of the presenting patient support potential contribution of the general risk factors of PAOD rather than underlying genetic influence for the development of atherosclerotic patch. Although we could not clarify the exact onset of PAOD, the combined effect of smoking, dyslipidemia, alcohol intake, and prolonged physical inactivity were likely to have contributed to the unusual development of PAOD in this patient.

Along with the gradual decrease of muscle strength, physical inactivity inevitably occurs in muscular dystrophies including DM1. It may accelerate the atherogenic process, and the recognition of typical claudication of occlusive arteriopathy can be delayed for the same reason. Consequently, the diagnosis of PAOD can be quite difficult in these patients.

In order to prevent PAOD in DM1, general risk factor modification including rehabilitation of physical inactivity and screening test are required. $\mathrm{ABI}$ is a useful firstline study for PAOD diagnosis [7].

Current PAOD treatment guideline recommends smok- 
ing cessation, antiplatelet and antithrombotic drugs, endovascular (balloon angioplasty, stent) and open surgical treatment for limb salvage depending on the severity of limb ischemia $[7,8]$. Conservative measures with antiplatelet and lifestyle modification are generally indicated as first-line therapy, but not fully efficient for critical limb ischemia. Single short stenosis or occlusion can be treated preferentially with endovascular techniques, nevertheless bypass surgery still presents the most common surgical approach for diffuse occlusive disease [8].

Although our patient fulfilled general indications of bypass grafting, we recommended conservative management as first-line therapy. Conservative management holds potential risk of PAOD progression that may induce limb necrosis, however the benefits may not outweigh the profound surgical risks in some cases. Despite our dissuasion, the patient insisted on the surgery. Bypass surgery was successful with improved arterial patency; however, post-operative pneumonia was developed and followed by respiratory arrest. After several failures of extubation and ventilator weaning, tracheostomy was performed. However, the patient did not recover from the cardiopulmonary complications.

There are several reports that preoperative exercise including pulmonary rehabilitation has a beneficial effect on surgical outcome [9]. Sufficient pre-operative conditioning with rehabilitation exercise improves surgical outcomes in cases of inevitable surgery.

Due to the known lower possibility of developing dyslipidemia or atherosclerosis, the occurrence of atherosclerosis can be overlooked in DM1 patients. Patients with adult-onset muscular dystrophies including DM1 may benefit from regular screening for relevant symptoms and signs of PAOD, and prompt referral for ABI in suspected cases. Furthermore, intensive surgical intervention should be reserved for the most severe limb threatening cases considering the high post-operative risks and the low expected activity level of the dystrophic patients.

\section{CONFLICT OF INTEREST}

No potential conflict of interest relevant to this article was reported.

\section{REFERENCES}

1. Rakocevic Stojanovic V, Peric S, Lavrnic D, Popovic S, Ille T, Stevic Z, et al. Leptin and the metabolic syndrome in patients with myotonic dystrophy type 1 . Acta Neurol Scand 2010;121:94-8.

2. Savkur RS, Philips AV, Cooper TA. Aberrant regulation of insulin receptor alternative splicing is associated with insulin resistance in myotonic dystrophy. Nat Genet 2001;29:40-7.

3. Udd B, Krahe R. The myotonic dystrophies: molecular, clinical, and therapeutic challenges. Lancet Neurol 2012;11:891-905.

4. Udd B, Meola G, Krahe R, Wansink DG, Bassez G, Kress W, et al. Myotonic dystrophy type 2 (DM2) and related disorders report of the 180th ENMC workshop including guidelines on diagnostics and management 3-5 December 2010, Naarden, The Netherlands. Neuromuscul Disord 2011;21:443-50.

5. Daniele A, De Rosa A, De Cristofaro M, Monaco ML, Masullo M, Porcile C, et al. Decreased concentration of adiponectin together with a selective reduction of its high molecular weight oligomers is involved in metabolic complications of myotonic dystrophy type 1. Eur J Endocrinol 2011;165:969-75.

6. Tsai JS, Guo FR, Chen SC, Lue BH, Chiu TY, Chen $\mathrm{CY}$, et al. Smokers show reduced circulating adiponectin levels and adiponectin mRNA expression in peripheral blood mononuclear cells. Atherosclerosis 2011;218:168-73.

7. Rooke TW, Hirsch AT, Misra S, Sidawy AN, Beckman JA, Findeiss LK, et al. 2011 ACCF/AHA focused update of the guideline for the management of patients with peripheral artery disease (updating the 2005 guideline). Vasc Med 2011;16:452-76.

8. Olin JW, Sealove BA. Peripheral artery disease: current insight into the disease and its diagnosis and management. Mayo Clin Proc 2010;85:678-92.

9. Valkenet K, van de Port IG, Dronkers JJ, de Vries WR, Lindeman E, Backx FJ. The effects of preoperative exercise therapy on postoperative outcome: a systematic review. Clin Rehabil 2011;25:99-111. 